\title{
Prognostic Value of Serum Hyaluronic Acid and Type I and III Procollagen Propeptides in Extrahepatic Biliary Atresia
}

\author{
PREMILA TRIVEDI, ANIL DHAWAN, JUHA RISTELI, LEILA RISTELI, MUDDASSAR MIRZA, \\ PAUL CHEESEMAN, AND ALEX P. MOWAT
}

Department of Child Health [P.T., A.D., M.M., P.C., A.P.M.] King's College Hospital, London, United Kingdom, and Departments of Clinical Chemistry [J.R.] and Medical Biochemistry [L.R.], University of Oulu, Oulu, Finland

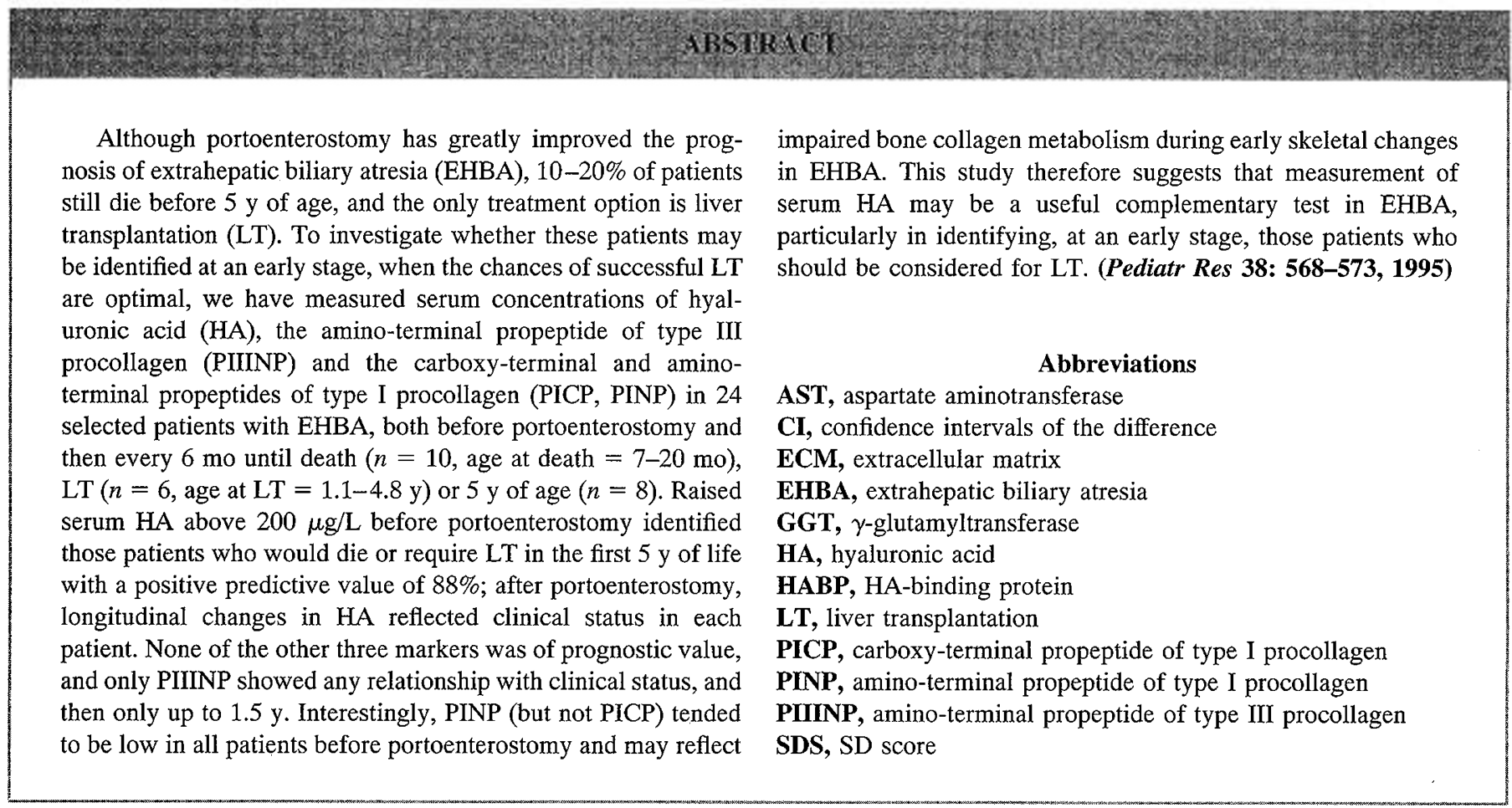

EHBA is the most common single cause of death due to liver disease in infancy (1). Disease progression can be arrested if bile flow is established by portoenterostomy (2), but if surgery is unsuccessful there is rapidly progressive intrahepatic fibrosis leading to cirrhosis and death generally within the first $2 \mathrm{y}$ of life $(1,2)$. Early identification of these patients in whom portoenterostomy will not succeed, and who should rather be considered for early LT, would therefore be of value in the management of EHBA. Inasmuch as the severity of intrahepatic fibrosis is a major determinant of disease activity and

Received October 6, 1994; accepted April 6, 1995.

Correspondence and reprint requests: Premila Trivedi, Department of Child Health, 4th Floor, New Ward Block, King's College Hospital, Denmark Hill, London SE5 8RS, UK. Supported in part by grants from The Children's Liver Disease Foundation and The Voluntary Research Trust of King's College Hospital and by The Finnish Cancer Foundation (J.R. and L.R.). prognosis in chronic liver disease (3), assessment of the rate of fibrogenesis could be useful in predicting outcome in conditions such as EHBA.

During hepatic fibrogenesis metabolism of ECM components, such as collagens (in particular collagens type I and III), glycoproteins, proteoglycans, and glycosaminoglycans, is increased within the liver (3). Measurement of serum concentrations of by-products of ECM metabolism has therefore been proposed as markers of hepatic fibrogenesis (4) and could be of value in assessing prognosis in chronic liver disease. For example, serum concentrations of the glycosaminoglycan HA and PIIINP have been shown to be of prognostic value in adults with primary biliary cirrhosis $(5,6)$.

Serum HA may also, as we have shown in preliminary studies (7), be useful in infants with cholestatic liver disease, but PIIINP is of no apparent value in infancy (8), maybe 
because the high levels normally found during growth mask any increase due to liver fibrogenesis (9). Because the PIIINP assay used in these early studies (10) measured several different antigens in serum (11), it is not clear whether a more specific assay would allow easier detection of PIIINP changes in pediatric liver disease. In recent years, we have developed such a PIIINP assay (12) and also assays for PICP and PINP $(13,14)$. These latter assays may be useful in assessing hepatic fibrogenesis, but have not yet been applied to either adult or pediatric liver disease.

The aim of this study was therefore to measure serum HA, PIIINP, PICP, and PINP in patients with EHBA, both before and serially after portoenterostomy, and to determine their value in the assessment of prognosis and disease activity in EHBA.

\section{METHODS}

Patients. Twenty four patients with EHBA (13 boys, 11 girls, assessed from $<4$ mo of age) were studied longitudinally, patients being selected as those in whom serial serum samples had been stored at $-20^{\circ} \mathrm{C}$ both before and after portoenterostomy. Patients were grouped for this study according to their outcome, group A consisted of 10 patients who died (age at death $=7-20$ mo of age, median 9), group B of six who required LT (age at LT $=1.1-4.8 \mathrm{y}$, median 2.6), and group C of eight who were jaundice-free and well at $5 \mathrm{y}$ of age (Table 1).

EHBA was diagnosed from clinical, biochemical, radiologic, and histologic findings and confirmed at laparotomy. At this stage, each group of patients had similarly raised serum bilirubin, AST, and GGT regardless of prognosis (Table 1). Portoenterostomy was performed in all patients between 2.5 and 16 wk of age, with significantly later surgery in group $A$ compared with groups B and C (Table 1; A versus $\mathrm{B} p<0.05$,

Table 1. Serum analysis before portoenterostomy and comparison normal range for age

\begin{tabular}{lccc}
\hline & $\begin{array}{c}\text { Group A } \\
(n=10)\end{array}$ & $\begin{array}{c}\text { Group B } \\
(n=6)\end{array}$ & $\begin{array}{c}\text { Group C } \\
(n=8)\end{array}$ \\
\hline HA SDS & $9.1 \pm 5.3$ & $8.4 \pm 4.5$ & $1.8 \pm 3.0$ \\
$p$ (95\% CI) & $*(7.5-10.7)$ & $*(7.0-9.8)$ & $*(0.7-2.9)$ \\
PIIINP SDS & $0.5 \pm 1.3$ & $1.9 \pm 0.4$ & $2.5 \pm 2.4$ \\
$p$ (95\% CI) & NS & $*(1.1-2.7)$ & $*(1.5-3.5)$ \\
PICP SDS & $-1.0 \pm 1.8$ & $0.5 \pm 2.0$ & $1.8 \pm 2.1$ \\
$p(95 \%$ CI $)$ & $* *(0.3-1.8)$ & NS & $*(0.9-2.7)$ \\
PINP SDS & $-3.1 \pm 1.3$ & $-3.1 \pm 0.9$ & $-1.8 \pm 1.8$ \\
$p(95 \%$ CI $)$ & $*(2.4-3.8)$ & $*(2.2-4.0)$ & $*(0.9-2.7)$ \\
Bilirubin $(\mu$ mol/L) & $178 \pm 72$ & $171 \pm 52$ & $138 \pm 20$ \\
$p$ (95\% CI) & $*(148-188)$ & $*(147-175)$ & $*(122-134)$ \\
AST (IU/L) & $232 \pm 96$ & $215 \pm 68$ & $215 \pm 108$ \\
$p$ (95\% CI) & $*(185-239)$ & $*(175-215)$ & $*(165-225)$ \\
GGT (IU/L) & $640 \pm 265$ & $892 \pm 501$ & $510 \pm 354$ \\
$p(95 \%$ CI) & $*(542-687)$ & $*(735-999)$ & $(389-581)$ \\
Age at portoenterostomy (wk) & $10.8 \pm 2.8$ & $8.0 \pm 1.2$ & $6.5 \pm 2.1$ \\
\hline
\end{tabular}

Values are mean \pm SD. $p(95 \% \mathrm{Cl})$ denotes the significance of the difference from the normal range for age, expressed as $p$ values and $95 \% \mathrm{CI}$ of the difference.

${ }^{*} p<0.001$.

${ }^{* *} p<0.03$.
95\% CI $=0.2-5.4$ wk; A versus $\mathrm{C} p<0.005,95 \% \mathrm{CI}=$ $1.8-6.8 \mathrm{wk})$.

After portoenterostomy, 9 of the 16 patients in groups $\mathrm{A}$ and $B$ showed an initial fall in serum bilirubin, although all went on to develop progressive liver disease and associated complications such as sepsis or gastrointestinal bleeding, resulting in death (at $10 \pm 4$ mo of age; mean \pm SD) in group $A$ or the need for LT (at $31 \pm 16$ mo of age; mean $\pm \mathrm{SD}$ ) in group $\mathrm{B}$. In contrast in group $\mathrm{C}$, serum bilirubin fell to normal in all patients after portoenterostomy and all remained clinically well during the first $5 \mathrm{y}$ of life, apart from one episode of suspected cholangitis.

Serum samples used for this study were obtained from each patient before portoenterostomy, at 6 mo of age and then at 6 monthly intervals until death, LT or $5 \mathrm{y}$ of age. Each sample was obtained primarily for management purposes and excess serum remaining after routine biochemical analysis was stored at $-20^{\circ} \mathrm{C}$ for between 1 and $4 \mathrm{y}$. We have previously found such storage conditions to have no effect on serum concentrations of HA, PIINP or PICP; stability of PINP could only be established over a 2-y period because the PINP assay has only been developed in the last 2 y (14). A total of 133 samples were available and consisted of 2-4 samples per patient (median 3) from subjects in group A, 2-8 per patient (median 6) in group B and 4-9 per patient (median 9) in group C.

Serum analyses. Serum concentrations of HA were measured using $100 \mu \mathrm{L}$ undiluted serum in a commercial radiometric assay (Pharmacia Diagnostics, Uppsala, Sweden) (15) in which HA in the sample bound to ${ }^{125}$ I-labeled specific HABP isolated from bovine cartilage $\left({ }^{125} \mathrm{I}-\mathrm{HABP}\right)$. Free ${ }^{125} \mathrm{I}-$ HABP was then bound to exogenously added HA covalently linked to Sepharose and the complex separated by centrifugation. The amount of bound radioactivity, which was inversely proportional to the amount of HA in the original serum sample, was then measured. Serum samples containing more than 350 $\mu \mathrm{g} \mathrm{HA} / \mathrm{L}$ fell outside the range of the standard curve and were therefore diluted with the zero HA standard solution and reassayed. The interassay coefficient of variation for the HA assay was $<10 \%$ (10 assays; serum HA concentrations 65 $\mu \mathrm{g} / \mathrm{L}$ and $453 \mu \mathrm{g} / \mathrm{L})$.

Serum concentrations of PIIINP (12) and PICP (13) were measured using $100 \mu \mathrm{L}$ of diluted serum in commercial RIA (Orion Diagnostica, Espoo, Finland), using a 1 in 6 dilution in PBS for serum samples obtained from patients less than 6 mo of age, 1 in 3 for samples at 6-12 mo of age and 1 in 2 for samples at $1-5 \mathrm{y}$ of age. For each assay, $100 \mu \mathrm{L}$ of the appropriate dilution were incubated with rabbit antibodies against either human PIIINP or PICP and ${ }^{125}$ I-PIIINP or ${ }^{125} \mathrm{I}$-PICP for $2 \mathrm{~h}$ at $37^{\circ} \mathrm{C}$. Bound ${ }^{125} \mathrm{I}$-PIIINP or ${ }^{125} \mathrm{I}$-PICP was then separated and measured, and the concentration of PIIINP or PICP in the original sample read from the appropriate standard curve. Interassay coefficients of variation were $<8 \%$ for both assays (10 assays; PIIINP at 2.1 and $12.5 \mu \mathrm{g} / \mathrm{L}$, PICP at 121 and $400 \mu \mathrm{g} / \mathrm{L})$.

Serum PINP was measured using a newly developed inhouse RIA, which uses rabbit antibodies against human PINP (14), ${ }^{125}$ I-PINP and $100 \mu \mathrm{L}$ of diluted serum, using dilutions of 1 in 100 for samples obtained from patients less 
than 3 mo of age, 1 in 25 for samples at 3-6 mo of age and 1 in 10 for samples at 6 mo-5 y of age. The interassay coefficient of variation was $<8 \%$ (10 assays; serum PINP at 82 and $462 \mu \mathrm{g} / \mathrm{L})$.

Because of the age variation in serum HA, PIINP, PICP, and PINP in healthy infants and children $(7,16-18)$, absolute values were corrected for age by conversion to SDS (Table 1) using control values previously obtained in this laboratory (7, 16-18). For this:

SDS

$=\frac{\text { observed value }- \text { mean for age and sex }=\text { matched controls }}{\text { standard deviation for age and sex-matched controls }}$

with the normal range (i.e. mean $\pm 2 \times \mathrm{SD}$ ) was defined as SDS -2.0 to SDS +2.0 .

Data analysis. Serologic data were found to be normally distributed within each group and parametric methods were therefore used for statistical analysis, using appropriate methods at each stage of follow-up. Before portoenterostomy, differences between groups were assessed using analysis of vari- ance, followed by $t$ tests. After portoenterostomy, the change between surgery and 6 mo of age for each of the three groups was assessed using the paired $t$ test. After 6 mo of age, longitudinal data for each patient was summarized as peak values (19) and differences between group summary values assessed using analysis of variance and $t$ tests. All statistical differences were expressed as $p$ values and $95 \% \mathrm{Cl}$ of the difference (20). The value of serum markers as early predictors of outcome were assessed using standard methods (21).

\section{RESULTS}

Serum concentrations of HA. Serum HA-SDS showed a different pattern both before and after portoenterostomy in patients with different outcomes. In those with a poor prognosis (group A and B), HA-SDS was significantly increased compared with normal before portoenterostomy (Table 1) and then increased even further in every child $(p<0.001,95 \% \mathrm{CI}=$ 24.1-83.5 for group A and 4.1-36.8 for group B) by 6 mo of age (Fig. 1). HA-SDS then remained high in these groups (Fig.
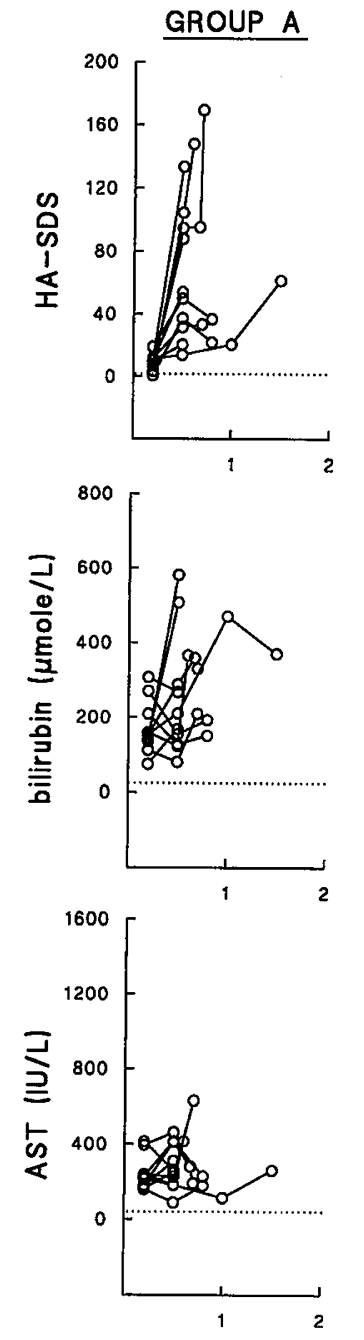

GROUP B
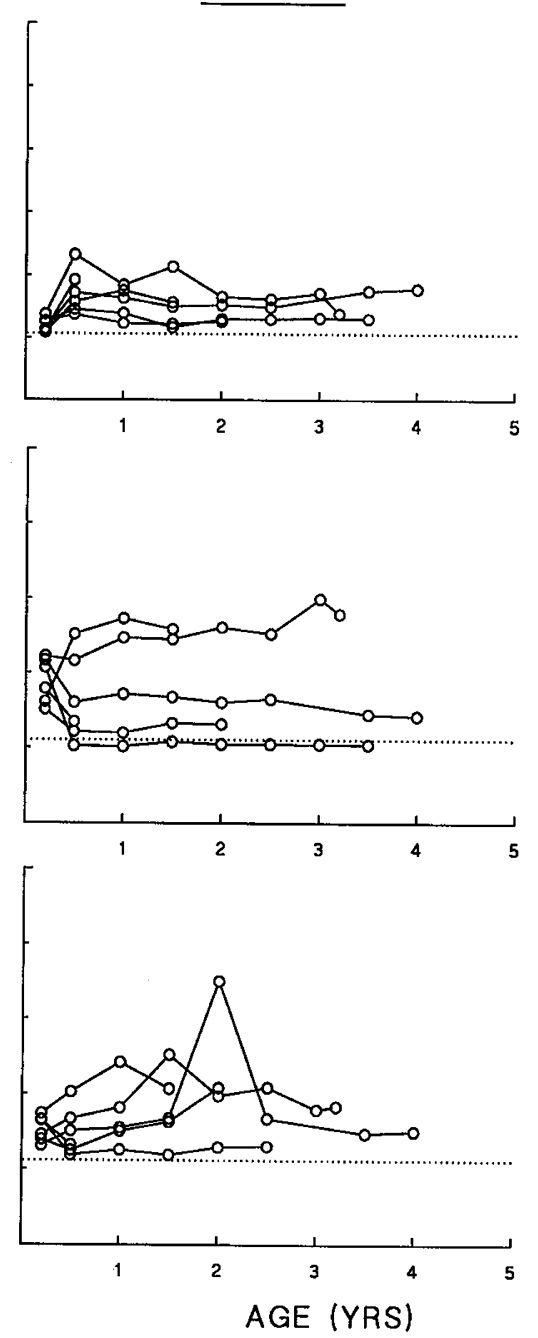

GROUP C
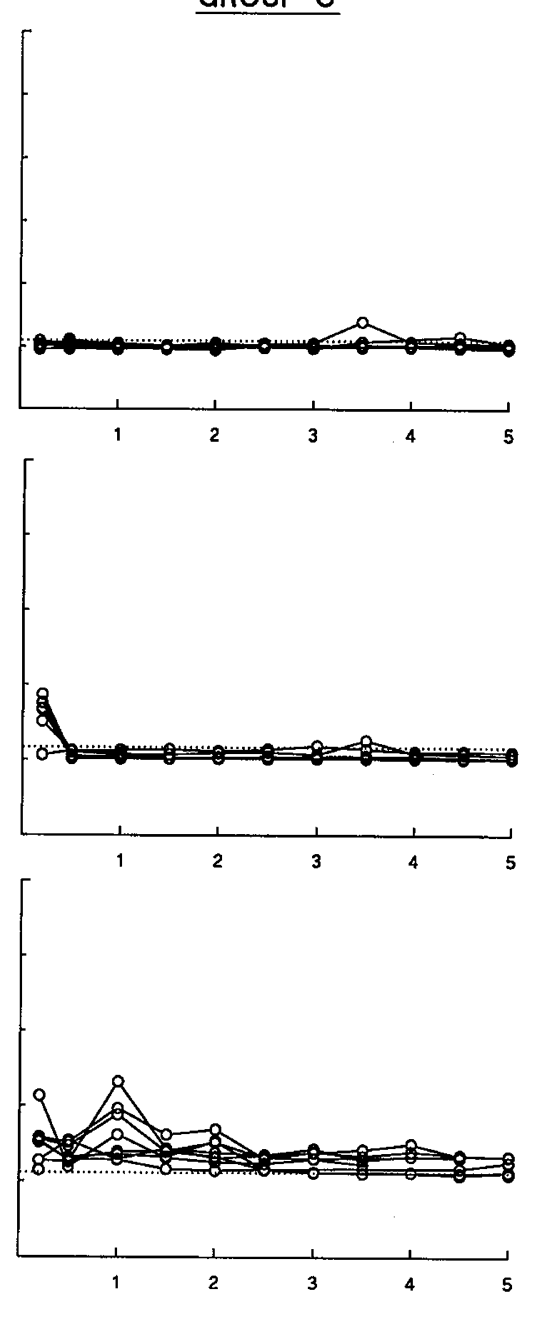

Fig. 1. Longitudinal changes in serum HA, bilirubin, and AST in groups A, B, and C during EHBA. Dotted line denotes upper limit of normal for age (i.e. +2.0 for HA SDS, $20 \mu \mathrm{mol} / \mathrm{L}$ for bilirubin, $40 \mathrm{IU} / \mathrm{L}$ for AST. Group A = patients who died at $10 \pm 4$ mo of age (mean \pm SD). Group B $=$ patients who had liver transplant at $31 \pm 16$ mo of age (mean $\pm \mathrm{SD}$ ). Group $\mathrm{C}=$ patients who were alive at $5 \mathrm{y}$. 
1) until either death (group A) or LT (group B), with generally higher values in group A. In contrast, those patients with a better prognosis (group C) showed relatively small increases in HA-SDS before portoenterostomy (Table 1), no significant change between surgery and 6 mo of age (Fig. 1), and then remained within the normal range for age during further follow-up, except for one isolated occasion in one patient (Fig. 1).

At every stage of follow-up, values of HA-SDS were greater in groups $\mathrm{A}$ and $\mathrm{B}$ compared with group $\mathrm{C}$ at every stage of follow-up (Fig. 1), with significantly greater values before portoenterostomy (Table 1; A versus $\mathrm{C}-p<0.005,95 \% \mathrm{CI}$ 2.8-11.8; B versus $\mathrm{C}-p<0.01,95 \% \mathrm{CI} 2.3-10.9$ ), at 6 mo of age (A versus $\mathrm{C}-p<0.001,95 \%$ CI 30.6-91.8; B versus $\mathrm{C}-p<0.001,95 \% \mathrm{CI} 15.6-39.8)$ and during further follow-up (A versus $\mathrm{C}-p<0.001,95 \%$ CI 28.5-90.4; B versus $\mathrm{C}-p<0.01,95 \% \mathrm{CI}=13.0-35.4)$.

Serum concentrations of PIIINP. Serum PIIINP SDS was similar in all three groups before portoenterostomy, regardless of outcome (Table 1). However, after surgery, those with a poor prognosis showed a different trend compared with those with a better prognosis. There was a significant increase in PIIINP SDS in group A after surgery $(p<0.01,95 \% \mathrm{CI}=$ 2.2-6.1) and in group B a trend toward an increase (Fig. 2). PIIINP SDS then remained high in both groups until 12-18 mo of age (Fig. 2), after which PIIINP fell to normal even though there was continuing clinical deterioration (Fig. 2). In contrast, group C showed a fall in PIIINP SDS to normal after surgery and then remained persistently normal (Fig. 2), except on two isolated occasions (Fig. 2), one of which coincided with raised HA and suspected cholangitis.

Serum concentrations of PICP. Serum PICP showed a mixed response in the three groups before portoenterostomy, with significantly decreased values in group $\mathrm{A}$, normal values in group $\mathrm{B}$ and raised values in group $\mathrm{C}$ (Table 1). After portoenterostomy however all three groups showed broadly the same trend irrespective of outcome, with normal PICP SDS throughout (Fig. 2).

Serum concentrations of PINP. Serum PINP SDS showed a similar trend in all three groups both before and after portoenterostomy, regardless of prognosis. PINP SDS was significantly decreased below the lower limit of normal for age in each group before surgery (Table 1), increased to values within the normal range by 6 mo of age $(p<0.001 ; 95 \% \mathrm{CI}$ $=1.1-4.2$ for group $\mathrm{A}, 1.0-4.5$ for group $\mathrm{B}$, and $0.2-4.3$ for group C). PINP SDS values then remained within the normal range during the rest of follow-up (Fig. 2).

Serum bilirubin, AST, and GGT. Serum bilirubin was similarly increased in all three groups before portoenterostomy
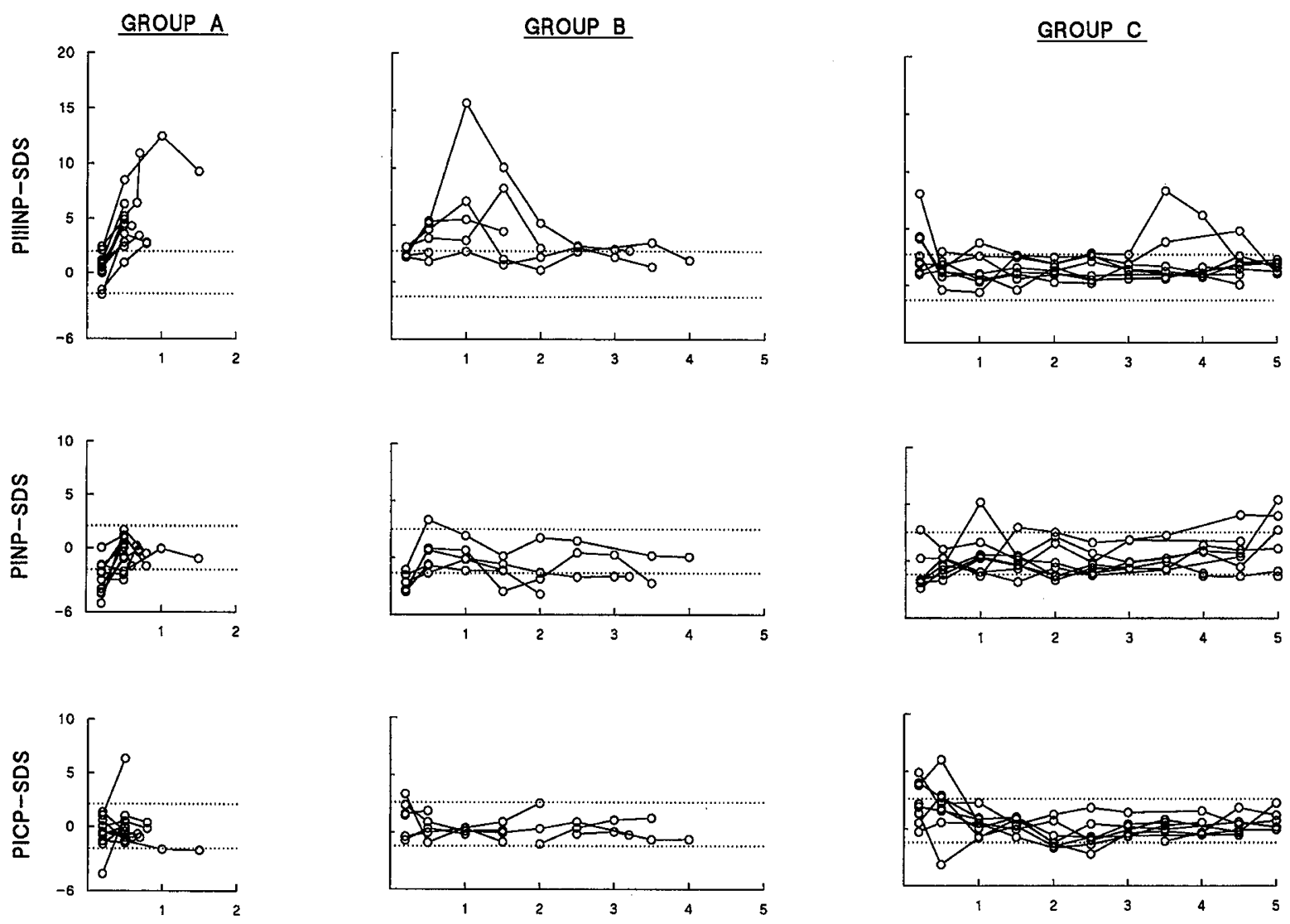

AGE (YRS)

Fig. 2. Longitudinal changes in serum PIIINP, PINP, and PICP in groups A, B, and C during EHBA. Dotted lines denote upper and lower limits of the normal range for age $(-2.0$ to +2.0$)$. Group $\mathrm{A}=$ patients who died at $10 \pm 4$ mo of age (mean $\pm \mathrm{SD}$ ). Group $\mathrm{B}=$ patients who had liver transplant at $31 \pm$ 16 mos of age (mean $\pm \mathrm{SD})$. Group $\mathrm{C}=$ patients who were alive at $5 \mathrm{y}$. 
(Table 1), but then showed a different trend after surgery depending on outcome (Fig. 1). Bilirubin fell in 4 of the 10 patients in group A and 5 of the 6 in group B (Fig. 1), but, except for one patient, did not become normal and remained raised throughout follow up (Fig. 1); in contrast, bilirubin fell to normal in all 8 patients in group $\mathrm{C}$ by 6 mo of age and remained normal throughout, except in one patient where an isolated increase in bilirubin was observed during an episode of suspected cholangitis.

Serum AST was similar in all three groups of patients regardless of prognosis both before portoenterostomy (Table 1), at 6 mo of age and during further follow-up (Fig. 1).

Serum GGT was similarly increased in all three groups before portoenterostomy regardless of prognosis (Table 1) but then remained unchanged by 6 mo of age in groups A and B, but rose significantly in group $\mathrm{C}(p<0.001,95 \% \mathrm{CI}=$ $118-505 \mathrm{IU} / \mathrm{L}$ ), and remained above normal in all three groups during the rest of follow-up (Fig. 1).

Relationship between serum analytes and prognosis. When assessed as a marker of prognosis, HA SDS was raised above 2.0 before portoenterostomy in 15 of 16 patients with a poor prognosis (groups $\mathrm{A}$ and $\mathrm{B}$ ), but only in 2 of 8 with a better prognosis (group C); HA SDS $>2.0$ therefore identified patients who would die (group A) or require LT (group B) with $88 \%$ positive predictive value $(95 \% \mathrm{CI}=64-99 \%)$ and $86 \%$ negative predictive value $(42-100 \%)$ with $94 \%$ sensitivity (70-100\%) and $75 \%$ specificity (35-97\%).

HA SDS at 6 mo of age was also of prognostic value, HA SDS $>2.0$ identifying patients who would die or require LT with a positive predictive value of $89 \%$ (65-99\%), negative predictive value of $100 \%(54-100 \%)$, sensitivity of $100 \%$ $(79-100 \%)$ and specificity of $75 \%$ (35-97\%); increasing the cut-off value of HA SDS to 4.0 increased all predictive values to $100 \%$. In addition, serum HA SDS at 6 mo of age also gave an idea of the time of survival, with significant correlations between age at death or LT and HA SDS $\left(r_{\mathrm{s}}=-0.58, p<\right.$ 0.03).

Serum bilirubin at 6 mo of age was also of prognostic value, values $>30 \mu \mathrm{mol} / \mathrm{L}$ identifying patients who would die or require $\mathrm{LT}$ with $100 \%$ positive predictive value $(78-100 \%)$, $89 \%$ negative predictive value $(52-100 \%), 94 \%$ sensitivity (70-99\%), and $100 \%$ specificity $(63-100 \%)$. However, it was notable that in contrast to HA SDS (which increased between surgery and 6 mo of age in all 16 patients with a poor prognosis; Fig. 1), serum bilirubin fell in 9 of the 16 patients over the same period (Fig. 1).

Values found for serum PIIINP, PICP, PINP, AST, or GGT were of no prognostic value either before or after surgery.

\section{DISCUSSION}

This study shows, for the first time, a serologic marker, HA, which may predict the outcome of EHBA, values of HA greater than $200 \mu \mathrm{g} / \mathrm{L}$ at diagnosis identifying with $88 \%$ positive predictive value those patients who will die or require LT before $5 \mathrm{y}$ of age. Although these results obviously need confirmation in a larger group of prospectively studied, unselected patients, they do indicate that early measurement of serum HA may be of potential major importance in assessing the prognosis of EHBA. Such prognostic information would be invaluable when planning management in EHBA, allowing time for patients with a poor prognosis and their families to be prepared for LT before the patient has developed end-stage liver disease and while the chances of successful LT are optimal (1).

Because no other serologic marker, including bilirubin (22), provides such clear-cut prognostic information in EHBA, we suggest that serum HA, which can be measured by a simple and reproducible assay and therefore lends itself readily to the routine clinical chemistry laboratory, be introduced into the profile of liver function tests currently performed when assessing and diagnosing EHBA. In addition, serum HA may also be a valuable adjunct to standard serologic tests during follow-up of EHBA, because longitudinal changes in HA found in this study were clearly related to clinical status.

In adult liver disease $(5,24)$, increases in serum HA have been largely attributed to impaired clearance of HA by damaged sinusoidal endothelial cells, which remove over $95 \%$ of HA from the circulation (23). A similar situation may also occur in EHBA. However, the raised serum HA observed in EHBA could also result, in part at least, from an increased output of HA from the liver during fibrogenesis, when the metabolism of many ECM components, including HA, is increased (3).

In addition to serum HA, we also investigated the role of other serum markers of ECM metabolism (4) in EHBA. Serum PIIINP was of no value in assessing prognosis before portoenterostomy, but did appear to be related to disease progression after portoenterostomy for the first 1-2 y of life. Thereafter, PIIINP fell to normal even in the presence of clinical deterioration, raising the possibility that the increases in PIIINP reflect increased output of PIIINP from the liver in the early stages of cirrhosis when type III collagen is formed very rapidly (25); the subsequent fall in PIIINP may later reflect the decline in type III collagen formation as cirrhosis becomes established and formation of type I collagen predominates (25). However, like HA, impaired clearance could also play a contributory role to raised serum PIIINP in EHBA, because this is cleared by scavenger receptors on hepatic sinusoidal endothelial cells (26) which may be damaged in EHBA. However, we suspect that decreased clearance may not significantly affect serum PIIINP in this study because serum PINP, which is cleared by the same receptor as PIIINP (27), was not increased with PIIINP in EHBA.

These normal or low concentrations of PINP found in this study (even in very severe disease) therefore at first were surprising because type I collagen metabolism is increased in EHBA as well as type III (28). We suggest that, inasmuch as type I collagen is found in bone as well as soft tissues and bone forms the largest pool of this collagen in the body, serum PINP is likely to be skeletal in origin (29). The low serum PINP seen in patients in this study could therefore be reflecting some early biochemical manifestation of bone disease, a common complication of cholestatic disease in infancy (30). Further studies in larger groups of EHBA patients, with and without overt bone disease, are needed to determine whether low serum PINP is 
related to bone metabolism and could have a clinical role in assessing skeletal abnormality in EHBA.

Another surprising finding in this study was that serum PICP did not show the same trend as PINP, even though both are released into the circulation in equimolar amounts during synthesis of type I collagen. The only obvious explanation for this discrepancy is that the two propeptides are cleared by different receptor mechanisms, PICP being cleared by the mannose receptor on liver sinusoidal endothelial cells (31) and PINP by the scavenger receptor on these same cells (27), which also clears PIIINP. Although highly speculative, we suggest that, in EHBA, both serum PINP and PICP are low due to a defect in bone metabolism; at the same time, the mannose receptor (which is more labile than the scavenger receptor) may be damaged resulting in impaired clearance of PICP. This means the low PICP due to decreased collagen metabolism in bone is counterbalanced by the increased PICP due to decreased clearance, resulting in normal serum PICP concentrations.

The findings of this study therefore allow us to conclude that serum HA may be a potentially important test in assessing, at an early stage, the prognosis in infants with EHBA. In addition, routine measurement of serum HA may also be a useful complementary test in monitoring EHBA, increases in HA, even in the presence of falling bilirubin, indicating disease progression. In contrast, serum PIIINP served as a marker of disease progression only in the first 18 mo of life and was of no prognostic value, whereas serum PICP was of no value at all in EHBA. Serum PINP was of no value in assessing liver disease but may prove to be useful in the biochemical assessment of skeletal abnormalities in EHBA; further studies are, however, required in larger numbers of patients to confirm this.

\section{REFERENCES}

1. Mowat AP 1994 Extrahepatic biliary atresia and other disorders of the extrahepatic bile ducts presenting in infancy. In: Mowat AP (ed) Liver Disorders in Childhood. Butterworths, London, pp 79-96

2. Ohi R, Hanmatsu M, Mochizuki I, Chiba T, Kasai M 1985 Progress in the treatment of biliary atresia. World J Surg 9:285-293

3. Gressner A 1991 Liver fibrosis: perspectives in pathobiochemical research and clinical outlook. Eur J Clin Chem Clin Biochem 29:293-311

4. Risteli L, Risteli J 1990 Non-invasive methods for the detection of organ fibrosis. In: Rojkind M (ed) Focus on Connective Tissue Research in Health and Disease, Vol 1. CRC Press, Boca Raton, FL, pp 61-98

5. Nyberg A, Engstrom-Laurent A, Loof L 1988 Serum hyaluronan in primary biliary cirrhosis-a biochemical marker of progressive liver damage. Hepatology 8:142-146

6. Babbs C, Smith A, Hunt LP, Rowan BP, Haboubi NY, Warnes TW 1988 Type III procollagen peptide: a marker of disease activity and prognosis in primary biliary cirrhosis. Lancet 1:1021-1024

7. Trivedi P, Cheeseman P, Mowat AP 1993 Physiological increase in serum hyaluronic acid in healthy infants and its value as a laboratory marker of progressive hepatobiliary disease in infancy. Clin Chim Acta 215:29-39
8. Trivedi P, Cheeseman P, Portmann B, Mowat AP 1986 Serum type III procollagen peptide as a non-invasive marker of liver damage in extrahepatic biliary atresia, idiopathic hepatitis of infancy and $\alpha-1$ antitrypsin deficiency. Clin Chim Acta 161:137-146

9. Trivedi P, Cheeseman P, Portmann B, Hegarty J, Mowat AP 1985 Variation in serum type III procollagen peptide in healthy subjects and its comparative value in the assessment of disease activity in children and adults with chronic active hepatitis. Eur $\mathrm{J}$ Clin Invest 15:69-74

10. Rohde H, Vargas L, Hahn E, Kalbfleisch H, Bruguera M, Timpl R 1979 Radioimmunoassay for type III procollagen peptide and its application to human liver disease. Eur J Clin Invest 9:451-459

11. Niemela O 1985 Radioimmunoassays for type III procollagen amino-terminal peptides in humans. Clin Chem 31:1301-1304

12. Risteli J, Niemi S, Trivedi P, Maentausta O, Mowat AP, Risteli L 1988 Rapid equilibrium radioimmunoassay for the amino-terminal propeptide of human type III procollagen. Clin Chem 34:715-718

13. Melkko J, Niemi S, Risteli L, Risteli J 1990 Radioimmunoassay of the carboxyterminal propeptide of human type I procollagen. Clin Chem 36:1328-1332

14. Risteli L, Melkko J, Jukkola A, Kauppila S, Smedsrod B, Risteli J 1992 Purification, assay and metabolic fate of the amino-terminal propeptide for human type I procollagen-the main collagen type of bone. J Bone Miner Res 7:S262

15. Brandt R, Hedlof E, Asman I, Bucht A, Tengbland A 1987 A convenient radiometric assay for hyaluronan. Acta Otolaryngol 442:31-35

16. Trivedi P, Hindmarsh P, Risteli J, Risteli L, Mowat AP, Brook CGD 1989 Growth velocity, growth hormone concentrations and serum concentrations of the aminopropeptide of type III procollagen. J Pediatr 114:225-230

17. Trivedi P, Risteli J, Risteli L, Hindmarsh P, Brook CGD, Mowat AP 1991 Serum concentrations of the type I and III procollagen propeptides as biochemical markers of growth velocity in healthy infants and children and in children with disorders of growth. Pediatr Res 30:276-280

18. Trivedi P, Risteli J, Risteli L, Mowat AP, Brook CGD, Hindmarsh P 1993 Serum markers of type $I$ collagen synthesis and degradation and growth. $J$ Endocrinol 137:P79

19. Matthews JNS, Altman DG, Campbell MJ, Royston P 1990 Analysis of serial measurements in medical research. Br Med J 300:230-235

20. Altman DG, Gardner MJ 1989 Calculating confidence intervals for means and their differences. In: Gardner MJ, Altman DG (eds) Statistics with Confidence. Universities Press, Belfast, pp 20-26

21. Griner PF, Mayewski RJ, Mushlin AI, Greenland P 1981 Selection and interpretation of diagnostic tests and procedures. Ann Intern Med 94:553-571

22. Mieli Vergani GM, Howard ER, Portmann B, Mowat AP 1989 Late referral for biliary atresia-missed opportunities for effective surgery. Lancet 1:421-423

23. Eriksson S, Fraser JRE, Laurent TC, Pertoft H, Smedsrod B 1983 Endothelial cells are a site of uptake and degradation of hyaluronan in the liver. Exp Cell Res 144:223-228

24. Babbs C, Haboubi NY, Mellor JM, Smith A, Rowan B, Warnes T 1990 Endothelial cell transformation in primary biliary cirrhosis. Hepatology 11:723-729

25. Rojkind M, Giambrone MA, Biempica L 1976 Collagen types in normal and cirrhotic liver. Gastroenterology 76:710-719

26. Smedsrod B 1988 Amino-terminal propeptide of type III procollagen is cleared from the circulation by receptor mediated endocytosis in liver endothelial cells. Collagen Relat Res 8:375-388

27. Melkko J, Hellevik T, Risteli L, Risteli J, Smedsrod B 1994 Clearance of $\mathrm{NH}_{2}$ terminal propeptides of types I and III procollagen is a physiological function of the scavenger receptor in liver endothelial cells. J Exp Med 179:405-412

28. De Freitas LAR, Chevallier M, Louis D, Grimaud J-A 1986 Human extrahepatic biliary atresia: portal connective tissue related to ductular proliferation. Liver 6:253261

29. Risteli L, Risteli J 1993 Biochemical markers of bone metabolism. Ann Med 25:385-393

30. Roberts CC, Book LS, Chan GM, Matlak ME 1981 Rickets in children with cholestatic liver disease: evaluation and treatment. Pediatr Res 15:544

31. Smedsrod B, Melkko J, Risteli L, Risteli J 1990 Circulating C-terminal propeptide of type I procollagen is cleared mainly via mannose receptors in liver endothelial cells. Biochem J 271:345-350 